\title{
Jean Boucher, La Vie et faits notables de Henry de
} Valois

\section{Michele Mastroianni}

\section{Q OpenEdition \\ 1 Journals}

\section{Edizione digitale}

URL: https://journals.openedition.org/studifrancesi/40517

DOI: 10.4000/studifrancesi.40517

ISSN: 2421-5856

Editore

Rosenberg \& Sellier

\section{Edizione cartacea}

Data di pubblicazione: 1 juillet 2004

Paginazione: 175

ISSN: 0039-2944

\section{Notizia bibliografica digitale}

Michele Mastroianni, «Jean Boucher, La Vie et faits notables de Henry de Valois», Studi Francesi [Online], 142 (XLVIII | I) | 2004, online dal 30 novembre 2015, consultato il 09 septembre 2021. URL: http:// journals.openedition.org/studifrancesi/40517 ; DOI: https://doi.org/10.4000/studifrancesi.40517

Questo documento è stato generato automaticamente il 9 septembre 2021.

\section{(c) (i) (9)}

Studi Francesi è distribuita con Licenza Creative Commons Attribuzione - Non commerciale - Non opere derivate 4.0 Internazionale. 


\title{
Jean Boucher, La Vie et faits notables de Henry de Valois
}

\author{
Michele Mastroianni
}

\section{NOTIZIA}

JEAN BOUCHER, La Vie et faits notables de Henry de Valois, édition critique établie et annotée par Keith CAMERon, Paris, Champion, 2003, pp. 207.

1 Pur non essendo un testo di grande valore letterario, la Vie et faits notables de Henry de Valois è un interessante esempio di biografia in funzione della propaganda politica, e riassume gran parte dei temi polemici, da parte della Ligue, contro quell'Enrico III che doveva poco dopo morire assassinato (la prima edizione è del 1589). Testo che usufruì, comunque, di almeno otto tirature e tre edizioni. Pubblicata anonima, questa Vie è stata attribuita, peraltro senza prove, a Jean Boucher, membro in vista della Ligue. L'attuale editore, Keith Cameron, non prende partito per l'attribuzione, ma sottolinea come questa biografia rispetti perfettamente le idee politiche e le argomentazioni di Boucher, che nel suo De Justa Henrici Tertii abdicatione e Francorum regno (pubblicato nello stesso anno) sviluppa una polemica affine. La Vie si presenta sotto forma di una banale biografia tradizionale, ma già il sottotitolo (Où sont contenues les trahisons, perfidies, sacrileges, exactions, cruautez et hontes de cet Hypocrite et Apostat, ennemy de la Religion Catholique) non lascia alcun dubbio sul carattere del libello e del suo scopo, che è quello di preparare i sudditi ad accettare l'idea di una deposizione, se non addirittura di un regicidio, in un momento in cui si fa un gran dibattere in area cattolica del tema del tirannicidio. Lo schema di questa Vie segue la traccia della precettistica classica del genere (Quintiliano), capovolgendone però le finalità celebrative con la sostituzione del biasimo alla laudatio e della rassegna dei vizi a quella delle virtù, con un mordente che sembra richiamare certe pagine di Svetonio ed evidenzia la forza sovversiva del pamphlet. Il testo attribuito a Boucher è pertanto un esempio di notevole interesse della propaganda basata sull'ingiuria, alla fine del regno del Valois, e permette di meglio comprendere i processi di diffamazione, utilizzati nelle campagne politiche delle guerre 
di religione in Francia. Permette anche di riflettere sulla fabbricazione di un mito in negativo, quello appunto degli ultimi Valois. L'edizione di Cameron si raccomanda per la precisione filologica, per l'accuratezza dell'annotazione e per l'introduzione, concernente sia la figura di Jean Boucher sia l'inquadramento generale del momento storico. 